\title{
Coordenadores pedagógicos: quem são esses profissionais?
}

\author{
Camila Castro Diniz' \\ Lélia Cristina Silveira de Moraes²
}

\section{RESUMO}

O presente artigo discute quem são os profissionais que atuam como coordenadores pedagógicos nas escolas da Rede Pública de Ensino do Maranhão focando o seu perfil profissional. Resulta de uma investigação qualitativa, de cunho bibliográfico e empírico, realizado em 2018. Participaram do estudo seis coordenadores pedagógicos dos municípios de São Luís, Rosário e Santa Inês- MA que integraram o Curso de Especialização em Coordenação Pedagógica, ofertado pela Universidade Federal do Maranhão (UFMA) e destinado a profissionais que atuam em equipes de gestão pedagógica nas escolas públicas de educação básica no estado. O aporte teórico teve a contribuição de autores como: Libâneo (2002, 2004), Placco, Almeida e Souza (2012), Paro (2010), Domingues (2009, 2014), entre outros. Como instrumento de coleta de dados, utilizaram-se entrevistas semiestruturadas e análises da ficha de inscrição dos coordenadores pesquisados, bem como o Relatório Final do Curso no Maranhão. Constatou-se, mediante os resultados, que nas diferentes redes escolares ainda é um desafio a construção de um perfil profissional que dê mais identidade a este profissional e que também garanta certa unidade a função do coordenador pedagógico. Neste ponto, devem-se criar condições concretas para a melhor qualificação destes profissionais e assegurar que nas escolas a especificidade desta função possa ser de fato, exercida.

Palavras-chave: Coordenadores Pedagógicos. Perfil Profissional. Educação básica.

\section{Pedagogical coordinators: who are these professionals?}

\begin{abstract}
This article discusses about the professionals that act as pedagogical coordinators in the public schools in Maranhão. It is the result of a qualitative, bibliographic and empirical investigation carried out in 2018. Six pedagogical coordinators from the municipalities of São Luís, Rosário and Santa Inês-MA who were part of the Specialization Course in Pedagogical Coordination offered by the Federal University of Maranhão (UFMA) and aimed at professionals who work in pedagogical management teams in public schools of basic education in the state. The theoretical contribution was based from the authors such as Libâneo (2002, 2004), Placco, Almeida and Souza (2012), Paro (2010), Domingues (2009, 2014), among others. It

\footnotetext{
${ }^{1}$ Mestre em Educação. Professora de Educação Infantil da Rede Municipal de Rosário-MA. Orcid iD: https://orcid.org/0000-0001-8106-6850. E-mail: camilacastrodiniz018@gmail.com 2 Doutora em Educação. Professora da Universidade Federal do Maranhão, Orcid iD: https://orcid.org/0000-0002-7330-553X. Email: lelia.silveira@ufma.br
} 
was used as an instrument of data collection, semi-structured interviews and analysis of the registration form of the coordinators surveyed, as well as the final report of the course in Maranhão. It was found, through the results, that it is still a challenge to build a professional profile that gives more identity to this professional and guarantee a certain unit in the function of the pedagogical coordinator. At this point, concrete conditions should be created for the better qualification of these professionals and ensure the specificity of this function can be actually applied in the schools.

Keywords: Pedagogical coordinators. Professional profile. Basic education.

\section{Coordinatoras pedagogicas: ¿quiénes son estos profesionales?}

\section{RESUMEN}

Este artículo analiza quiénes son los profesionales que actúan como coordinadores pedagógicos en las escuelas de la Red de Escuelas Públicas de Maranhão principalmente, su perfil profesional. Es el resultado de una investigación cualitativa, bibliográfica y empírica, realizada en 2018. Fue realizada con seis coordinadores pedagógicos de los municipios de San Luis, Rosário y Santa Inés-MA que formaron parte del Curso de Especialización en Coordinación Pedagógica, ofrecido por la Universidad Federal de Maranhao (UFMA) y dirigido a profesionales de los equipos de gestión pedagógica de las escuelas públicas de educación básica del estado. La contribución teórica más importante ha sido de autores como: Libéneo (2002, 2004), Placco, Almeida y Souza (2012), Paro (2010), Domingues (2009, 2014), entre otros. Como instrumento de recopilación de datos, se utilizaron entrevistas semiestructuradas y análisis de formularios de los registros de los coordinadores encuestados, así como el informe final del curso en Maranhao. Se encontró, a través de los resultados, que en las diferentes redes escolares sigue existiendo el reto de construir un perfil profesional que conceda más identidad al profesional y que garantice a una determinada unidad, ejercer la función de coordinador pedagógico. En este punto, deben crearse condiciones concretas para una mejor cualificación de estos profesionales y garantizar que en las escuelas se pueda ejercer realmente la especificidad de esta función.

Palabras llave: Coordinadores Pedagógicos. Perfil profesional. Educación básica.

\section{Introdução}

Neste artigo, discutimos quem são os profissionais que atuam como coordenadores pedagógicos nas escolas da Rede Pública de Ensino do Maranhão focando o seu perfil profissional. Tal investigação, de abordagem qualitativa, integra uma pesquisa mais ampla e concluída em 20183, que

3 Os dados referentes a este artigo fazem parte da pesquisa intitulada "Formação continuada e prática de coordenadores pedagógicos no Maranhão: em cena o programa nacional escola de gestores", cujo objetivo geral foi analisar a formação continuada desenvolvida no curso de especialização em Coordenação Pedagógica,

Revista Exitus, Santarém/PA, Vol. 10, p. 01- 29, e020090, 2020. 
envolveu a participação de seis coordenadores pedagógicos oriundos do Curso de Especialização em Coordenação Pedagógica. Esse curso, implementado pela UFMA e desenvolvido no âmbito do Programa Nacional Escola de Gestores ${ }^{4}$ evidenciou que há uma preocupação crescente com relação ao perfil dos profissionais que exercem a função de coordenadores pedagógicos. Deste modo, é que o presente artigo traz como problemática de estudo: qual é o perfil profissional do coordenador pedagógico das escolas públicas de educação básica?

Como subsídio a essa discussão, realizamos primeiramente breves considerações a respeito da pesquisa que originou este artigo, seguida da discussão do perfil profissional do coordenador pedagógico a fim de situarmos a questão. Em seguida, apontando seus resultados, destacamos o perfil desejado para o egresso do Curso de Especialização em Coordenação Pedagógica, além de outros achados referentes às contribuições do curso e perfil dos coordenadores participantes no Maranhão. Por último, apresentamos algumas considerações conclusivas.

No que diz respeito à metodologia, com base em Minayo (2010), compreende-se que o processo de trabalho numa pesquisa qualitativa integra especialmente três etapas: a fase exploratória, o trabalho de campo e a análise e tratamento do material empírico. Neste artigo, para análise teórica, recorremos à pesquisa bibliográfica por meio de autores como: Libâneo (2002, 2004), Placco, Almeida e Souza (2012), Paro (2010), Domingues (2009 2014). A pesquisa documental foi realizada com base na ficha de inscrição dos coordenadores participantes, assim como no relatório final do Curso no Maranhão. Já as entrevistas semiestruturadas, que favorecem uma estreita relação com os sujeitos de pesquisa, também foram utilizadas como um instrumento privilegiado de informação (RICHARDSON,

ofertado pela UFMA e suas repercussões sobre a prática pedagógica dos coordenadores egressos.

${ }^{4}$ Segundo o Ministério da Educação (BRASIL, [201-]), este programa foi constituído com o propósito de qualificar gestores das escolas da educação básica pública. O seu surgimento integra um conjunto de ações que teve início em 2005, com o curso - piloto de extensão em gestão escolar (100) horas, ofertado pelo Instituto Nacional de Estudos e Pesquisas Educacionais (INEP). Mais informações no site: http://portal.mec.gov.br/component/tags/tag/33600. Acesso em 26 abr. 2019. 
1999; POUPART, 2010). Assim, a partir do estudo de caso que se configura numa "[...] visão holística do fenômeno estudado" (ALVES-MAZZOTTI, 2006, p. 650) optou-se por realizar a pesquisa com os coordenadores pedagógicos egressos das cidades de São Luís, Rosário, Morros e Santa Inês-MA.

Por hora, pode-se acentuar que a discussão sobre a coordenação pedagógica tem se configurado como pauta recente nos debates que envolvem a educação. Nisso, reside a importância de tomar este profissional como eixo norteador de pesquisa, pois reconhecendo o seu trabalho como fundamental para a melhoria da escola pública, desejamos possibilitar um constante repensar sobre o seu trabalho, identidade e desenvolvimento profissional.

\section{O perfil profissional do coordenador pedagógico: situando a questão}

Considerando a luta histórica, no Brasil, por uma educação pública, laica e democrática, faz-se mister, discorrer a respeito do coordenador pedagógico e sobre o que deve caracterizar o seu perfil profissional, uma vez que as exigências atuais no tocante à organização e ao funcionamento das escolas trazem novas implicações ao seu trabalho e a de seus pares.

Libâneo (2004, p. 215), em estudo sobre a gestão escolar revela que a "[...] coordenação é um aspecto da direção, significando a articulação e a convergência do esforço de cada integrante de um grupo [...]". Nessa linha de raciocínio, segundo Paro (2010, p. 17), "[...] à coordenação cabe a utilização racional do esforço humano coletivo". Assim, embora o coordenador pedagógico seja um agente fundamental para coordenar e acompanhar as atividades didático-pedagógicas no espaço escolar, a sua função deve promover a participação de todos, escola e comunidade, na construção de uma educação pública de qualidade.

Dito de outro modo,

[...] O trabalho de coordenação é um trabalho de integração, de envolvimento, de coletividade e de comprometimento sua função vai bem quando todos se entendem na perseguição dos objetivos educacionais, capazes de promover educação de qualidade e acessível a todos que a buscam (RIBEIRO, 2016, p. 63). 
Historicamente, cabe acrescentar, que este profissional realizava as atividades que antes desempenhavam o inspetor e o supervisor escolar. Para Santos $(2014$, p. 2),

[...] no decorrer do século XX e, sobretudo, no auge do tecnicismo da década de 1970. A figura do coordenador pedagógico, revestida dos cargos de supervisão, orientação e inspeção escolar simbolizava o controle e a hierarquização do poder.

Contudo, nos últimos anos, em detrimento das inúmeras mudanças na sociedade e com o Estado eximindo-se cada vez mais de suas responsabilidades, hoje, mais do que nunca este profissional é chamado a desempenhar um papel pluridimensional (CHÚ, 2012). Portanto, esta função é exercida pelo licenciado com especialização na área e/ou pelo pedagogo, visto ser ele o profissional que atua em várias instâncias da prática educativa, inclusive, em atividades de organização/ gestão e coordenação pedagógica nas escolas.

De acordo com Placco, Almeida e Souza (2012), em função da gestão democrática e participativa, a atividade deste profissional, sem dúvida, deve envolver a articulação dos processos educativos, a formação de professores e a transformação das práticas escolares. Em sua função de articulador, ele deve contribuir com a construção de uma prática educacional integral e humanizadora permitindo a aproximação da comunidade escolar com os princípios que regem o projeto político da escola e a sua realidade social mais ampla. Como formador, sua responsabilidade maior estaria na preparação em serviço dos professores: ouvindo, discutindo e levantando questões relevantes para o aprimoramento de novas posturas e olhares no que diz respeito ao processo de ensino-aprendizagem. E como transformador, a sua contribuição está no desvelamento de forças e contradições que envolvem o cotidiano escolar, em detrimento de um espaço formativo mais justo, igualitário e reflexivo.

Contudo, a este respeito, Domingues (2009, p. 18) faz a seguinte colocação, em certos estados, na prática, a função do coordenador ainda vem sendo exercida pelo supervisor escolar. 
[...] Em outros, esse cargo ou função, não existe e nos casos em que os estados ou municípios adotam a figura do coordenador pedagógico, as condições de trabalho são tão diversas que se torna difícil estabelecer relações entre as ações destes profissionais.

Logo, nas escolas públicas brasileiras pode-se evidenciar que estes sujeitos encontram situações adversas para assumir a função de coordenadores pedagógicos. E neste ponto, o problema persiste em função dos "[...] inúmeros papéis que estes assumem diariamente, tornando-se praticamente impossível definir as atribuições do mesmo [...]" (FORTUNA, 2011 , p. 6). Já que essa função está em construção e é formada por indivíduos de diferentes perfis profissionais, segundo cada rede de ensino.

Na percepção de Salgueiro (2014), o conceito de "profissional" é polissêmico, podendo revestir-se de diversos significados com abordagens possíveis e nem sempre conciliáveis. Ainda assim, embora haja uma multiplicidade de perspectivas, segundo o autor, o perfil profissional:

[...] deve ser visto como uma representação de caraterísticas essenciais que descrevem as ações/atividades e as circunstâncias em que um profissional as executa num determinado contexto. Estas caraterísticas podem ser identificadoras, definidoras, qualificadoras e integradoras da descrição de um perfil profissional e servem, sobretudo, como um instrumento referenciador (SALGUEIRO, 2014, p. 20).

Consequentemente, esse perfil significa um conjunto de referenciais comuns para o reconhecimento de certas competências ou características a serem desempenhadas por um determinado profissional. Mas no caso dos coordenadores, têm-se constatado que a sua atuação é complexa e contraditória. Além disso,

[...] esta questão do perfil assumido por cada coordenador traduz significativamente a questão da subjetividade do profissional considerando que não há como separar a sua prática escolar dos conceitos e experiências que este sujeito coordenador traz consigo (FORTUNA, 2011, p. 7).

Deste modo, é que enfrentamos o desafio atual de delinear um perfil profissional para este sujeito escolar, visto que a sua atuação depende de inúmeros fatores e variáveis inerentes ao processo de ensino-aprendizagem. Para além, então, de algumas metáforas relacionadas a essa função, como a do: "faz-tudo", "apagador de incêndios" ou "fiscal" dos professores e das 
rotinas escolares, defende-se a construção de um perfil que garanta certa unidade na atuação do coordenador pedagógico e que colabore para a constituição de sua identidade numa perspectiva crítica e emancipatória.

Tais questões remetem à sua formação, uma vez que estes sujeitos se tornam profissionais à medida que buscam a melhoria da sua qualificação. Evidentemente, a formação é um processo contínuo e permanente de desenvolvimento pessoal e profissional, sendo a formação inicial apenas o princípio desta profissionalidade. Conforme Libâneo (2002), a reflexão a respeito da prática escolar deve estar aliada à formação docente, pois o embasamento teórico Ihe dará subsídios para pensá-la criticamente e melhorá-la propondo novas alternativas pedagógicas.

Nessa direção, além da formação inicial é fundamental que o coordenador pedagógico tenha acesso a uma formação contínua de qualidade. Placco, Souza e Almeida (2012), sobre esta análise acrescentam que diferente do professor, cuja especificidade é o ensinar, o coordenador pedagógico necessita de uma formação específica. E sobre isso, é preciso questionar: quem é o formador deste profissional ou quais instâncias tem se constituído como espaço de formação do coordenador pedagógico?

Não nos eximindo deste debate, acreditamos que em meio ao movimento neoliberal, o campo da formação dos profissionais da educação tem se tornado refém do mercado e isto, sem dúvida, contribui para precarização e proletarização da carreira docente, cuja polivalência de seus trabalhadores tem se tornado crescente. Segundo Vieira $(2015$, p. 3),

[...] para além da polivalência disciplinar, evoca-se do pedagogo a polivalência profissional, herança do modo de produção capitalista, pois é necessário ao docente, fazer o máximo possível com o mínimo de recursos! Em síntese, a educação deixa de ser um direito social de todos e se torna um bem de consumo de alguns, na mesma proporção em que o aluno é um cliente a ser atendido e o professor um tarefeiro a serviço do estado neoliberal.

Na visão de outros autores, tais como: Duarte (2003), Freitas (2014), Ghedin (2002), temos diante disso, o retorno da concepção pragmática de formação, aquela que se baseia apenas na atividade prática ou em competências e que não oportuniza uma reflexão crítica e transformadora 
da realidade, só possível mediante uma formação que também valorize a reflexão filosófica e o conhecimento científico.

Longe, então, desta formação de professores que trabalha no pêndulo, ora da teoria sem prática e ora da prática sem teoria (VIEIRA, 2015), que chamamos atenção para um projeto formativo que esteja pautado na práxis, na qual teoria e a prática possam ser trabalhadas de forma articulada e indissociável. Vázquez (1997), tomando por base Marx, nos diz que a próxis deve ser compreendida como uma categoria central da filosofia, vista como uma atividade teórico-prática que se concebe não apenas como interpretação do mundo, mas como um guia para sua transformação, pois envolve um trabalho de consciência "[...] passagem indispensável para desenvolver ações reais, efetivas" (p. 207).

Logo, é a partir desta ação conjunta entre teoria e prática que se pode possibilitar uma formação emancipatória do coordenador pedagógico e dos demais profissionais da educação. Sendo necessário também considerar as demandas e necessidades do contexto de seu trabalho, valorizar sua função e os eixos que a articulam (PLACCO; SOUZA; ALMEIDA, 2012).

\section{- perfil profissional dos coordenadores pedagógicos que atuam na educação básica do estado do Maranhão}

Visto que "[...] a busca por uma identidade profissional ou mesmo um perfil ocupacional comum do coordenador pedagógico apresenta-se como um desafio em todo o território nacional" (BRASIL, 2009, p. 6), torna-se relevante, neste momento, traçar o perfil profissional dos egressos do Curso de Especialização em Coordenação Pedagógica. Antes, porém, convém ressaltar que, no Maranhão, o referido curso inserido no Programa Nacional Escola de Gestores e implementado pela UFMA, ocorreu no período de 2015 a 2016 e envolveu a participação de 10 polos - São Luís (polos 1 e 2), Rosário, Pinheiro, Itapecuru-Mirim, Santa Inês, Bacabal, Codó, Presidente Dutra e São João dos Patos - contemplando 75 municípios do estado do Maranhão. 
Com auxílio do MEC e outros parceiros locais, como das Secretarias Municipais e Estadual de Educação (Semed/ Seduc-MA), União Nacional dos Dirigentes Educacionais (UNDIME) e do PPGE/ UFMA, o seu objetivo era formar, em nível de pós-graduação lato sensu, coordenadores pedagógicos que atuavam em instituições públicas de educação básica, no Maranhão, visando à ampliação de suas capacidades de análise; resolução de problemas, elaboração; desenvolvimento de projetos e de atividades no âmbito da organização do trabalho pedagógico e do processo de ensinoaprendizagem (DINIZ, 2018). Do ponto de vista de Azevedo et al. (2017), com a natureza deste curso se reconhece a importância da gestão escolar, principalmente da ação do coordenador pedagógico para promover o sucesso das ações educativas.

Então, seguindo a maior parte das recomendações do MEC, esse curso foi desenvolvido na modalidade à distância, via plataforma moodle, com um total de 420 horas $^{5}$ (carga horária superior à proposta pelo MEC de 405 horas) e apresentação de TCC em forma de monografia.

Sobre a plataforma moodle, de acordo com Silva (2015), é possível encontrar diversos recursos para a interação entre o formador e o formando, e entre todos os participantes do ambiente, uma vez que este espaço não limita as possibilidades de interação somente à postagem de textos, imagens, links ou vídeos, mas oferece além de espaços de comunicação, momentos de reflexão e avaliação pelos cursistas.

A equipe de trabalho do curso foi composta por dois coordenadores gerais (doutores); uma secretária; dois técnicos de informática e uma supervisora dos tutores, pertencente à Semed. Já a equipe pedagógica, era formada por 10 tutores presenciais (especialistas) e 62 professores (mestres e doutores) que, em sua maioria, pertenciam ao quadro de professores da UFMA. Desse grupo de professores, apenas 31 ministraram disciplinas, 10

5 Devido a primeira sala/ disciplina de Introdução ao Ambiente Virtual- ICAV ter sido trabalhada com uma carga horária maior (30 horas) para atender as necessidades dos cursistas. 
foram escolhidos para coordenar salas ambientes/disciplinas e os demais foram incorporados no processo de orientação de monografias (DINIZ, 2018).

Nessa direção, convém ressaltar que o ensino a distância mediado pelo uso das tecnologias de informação e comunicação vem sendo utilizado como uma alternativa possível para ampliar a oferta de cursos de formação continuada e pós-graduação, principalmente em localidades em que a oferta de formações alternativas se encontra insuficiente (BRASIL, 2009).

A fim de abranger temáticas, cujo foco fosse a intervenção do coordenador pedagógico no espaço da escola e da sala de aula, a organização curricular do curso estruturou-se por meio de 10 Salas Ambiente/Disciplinas, de no mínimo 30 horas e no máximo 45 horas de carga horária, a partir de três ciclos temáticos denominados: Organização e Gestão do Trabalho Pedagógico (105 h/a); Projeto Pedagógico e Avaliação (135 h/a); Práticas e Aprendizagem Escolar (180 h/a) (DINIZ, 2018). Com isso, buscou-se fortalecer a função do coordenador pedagógico com ênfase em sua dimensão mobilizadora e articuladora para a melhoria da qualidade de ensino.

Tomando por base a Resolução n¹265/2015 referente aos cursos de especialização da UFMA, a frequência dos cursistas era aferida conforme a sua participação nos encontros presenciais. E a avaliação dos mesmos ocorria de forma permanente, por meio de relatórios e atividades no ambiente moodle atribuindo-se notas de 0 a 10. Em se tratando do Trabalho de Conclusão do Curso, como já evidenciado, este ocorreu mediante a produção e apresentação de monografias, envolvendo o contexto de trabalho dos coordenadores em articulação com as temáticas que foram desenvolvidas ao longo do curso. Importante frisar, que essa etapa foi caracterizada por demasiadas dúvidas e receios por parte dos cursistas, pois para muitos era a primeira vez que engendravam um trabalho dessa natureza, na qualidade de autores (UNIVERSIDADE FEDERAL DO MARANHÃO, 2017). 
Deste modo, em termos quantitativos, a primeira turma desta experiência no Maranhão iniciou com 400 cursistas e finalizou com cerca de 294 especialistas, tendo um percentual de evasão considerado baixo, $(29,07 \%)$ e um total de aproveitamento bastante positivo se comparado a outras formações realizadas a distância $(73,5 \%$ ) (UNIVERSIDADE FEDERAL DO MARANHÃO, 2017). Segundo o MEC, dentre o perfil desejado para o egresso do curso esperava-se que o coordenador pedagógico fosse capaz de:

\begin{abstract}
-Aprofundar a compreensão da educação escolar como direito fundamental do cidadão e como instrumento de emancipação humana no contexto de uma sociedade com justiça social;

-Comprometer-se com a qualidade do trabalho pedagógico desenvolvido na escola, participando dos processos de elaboração, implementação e avaliação do Projeto Político-Pedagógico e assegurando a participação efetiva de toda a comunidade escolar;

- Incentivar o desenvolvimento de práticas educativas que promovam a melhoria do processo de ensino-aprendizagem, a articulação e a integração das ações pedagógicas;

- Participar do fortalecimento da gestão democrática do ensino por meio da construção do trabalho coletivo e da articulação da unidade escolar com as diretrizes propagadas pelo sistema de ensino;

- Compreender a realidade escolar e a gestão dos processos educativos nas dimensões social, política, cultural, econômica e pedagógica.

- Valorizar a vivência investigativa e a busca do aperfeiçoamento profissional contínuo;

- Compreender os meios de comunicação como espaços de produção, socialização e disseminação de informações, saberes, conhecimentos e culturas e, portanto, como possibilidades de descentralização de poderes e de promoção da autonomia;

- Dominar e utilizar ferramentas tecnológicas no campo da organização dos processos de trabalho nos sistemas e unidades de ensino, tomando-as como importantes ferramentas para realização da gestão democrática da educação. (BRASIL, 2009, p.9).
\end{abstract}

No caso da UFMA, apesar de uma parcela dos egressos terem se afastado da função, principalmente por questões de ordem política, já que a coordenação pedagógica continua atrelada a práticas de mando e desmando típicas de uma sociedade patrimonialistas e clientelistas, como é - caso do Brasil (SOUZA, 2016). Acreditamos que foi dada a estes profissionais, a oportunidade de terem acesso a uma formação diferenciada baseada, sobretudo, na gestão democrática e na reflexão do trabalho pedagógico.

Revista Exitus, Santarém/PA, Vol. 10, p. 01- 29, e020090, 2020. 
Logo, é possível destacar que o grande diferencial desta formação esteve no apoio das instituições parceiras empenhadas em proporcionar a municípios distantes a formação do coordenador pedagógico e no engajamento de toda a equipe de trabalho compromissada em rever e repensar novas estratégias que pudessem proporcionar um ambiente agradável de interação e motivação aos cursistas (DINIZ, 2018).

Contudo, apesar do potencial pedagógico das tecnologias é importante também frisar que houve certas dificuldades atreladas a elas nesta formação, como por exemplo: obstáculos relacionados ao acesso da internet em certos municípios e pouca intimidade de alguns cursistas com o uso das tecnologias, os impossibilitando de conciliar suas atividades diárias com as atividades do curso (DINIZ, 2018). E na prática, embora esta formação tenha contribuído com um aporte teórico fundamental para ações reflexivas e transformadoras dos cursistas, estes profissionais ainda concentram em suas mãos as decisões mais urgentes nas escolas. Nesse caso, a sua função primeira de formação em serviço dos professores continuava em segundo plano, sofrendo fortes influências do sistema que, por vezes, está disposto a manter os interesses do setor privado (DINIZ, 2018).

Portanto, a realização deste curso significou apenas um começo de uma grande jornada no que tange às políticas públicas de formação destinadas à equipe gestora, no Maranhão, já que os egressos apesar de terem adquirido novos hábitos de estudos e modificados as suas posturas, tornando-se mais autônomos, disciplinados e seguros de seu papel, em suas realidades ainda enfrentam grandes dilemas para dar um novo sentido a esta função (DINIZ, 2018).

Isto posto, na tentativa de delinear o perfil profissional dos coordenadores pesquisados, além de aspectos como: localidade, sexo, idade e rede de ensino em que atuam também se levou em consideração destes sujeitos: formação acadêmica, tempo de exercício na função como professores, coordenadores pedagógicos e carga horária de trabalho.

No quadro 1, a seguir, explicitamos a primeira identificação a qual nos referimos destes sujeitos. 
QUADRO 1 - Identificação dos coordenadores pedagógicos por localidade, sexo, idade, rede de ensino e etapa/ modalidade de ensino em que atuam

\begin{tabular}{|c|c|c|c|c|c|}
\hline $\begin{array}{c}\text { Coordenador } \\
\text { pedagógico }\end{array}$ & Localidade & \multicolumn{1}{|c|}{ Sexo } & Idade & $\begin{array}{c}\text { Rede de } \\
\text { Ensino }\end{array}$ & $\begin{array}{c}\text { Etapa /modalidade } \\
\text { de ensino }\end{array}$ \\
\hline C1 & São Luís & Masculino & 38 anos & Estadual & $\begin{array}{l}\text {-Ensino Fundamental II } \\
\text { (apenas o } 9^{\circ} \text { ano) }\end{array}$ \\
\hline C2 Ensino Médio
\end{tabular}

Fonte: Diniz (2018).

Nota-se, que o conjunto dos coordenadores pesquisados é formado por mulheres e apenas um homem, com faixa de idade que varia entre 36 a 54 anos, sendo que apenas duas das coordenadoras entrevistadas possuem mais de 50 anos de idade. Em sua maioria, coordenam na rede estadual de ensino, com exceção da coordenadora C5 que pertence à rede municipal. E o nível de ensino ou modalidade em que atuam é variado, pois há 2 (dois) coordenadores pedagógicos que atuam com 0 público do ensino fundamental, outras duas, trabalham com o público da EJA e os demais, no ensino médio regular.

Todos estes coordenadores, importante acrescentar, pertencem a escolas da rede pública do Maranhão que possuem basicamente o mesmo corpo administrativo e pessoal, consideradas de pequeno e grande porte. Em algumas destas escolas, contudo, não há oficialmente a figura do coordenador pedagógico e sim, do supervisor escolar com a presença também em uma delas do apoio ou agente pedagógico.

Fica expressa, então, como já indicava a literatura trabalhada que no cenário da escola pública a atuação do coordenador pedagógico continua em fase de consolidação, com a presença marcante em algumas 
escolas de certas funções e nomenclaturas que caracterizaram a sua história.

\section{Como se tornaram coordenadores pedagógicos}

Assim como Dotta et al. (2011, p. 575), acreditamos que é possível conhecer diferentes formas identitárias dentro de um mesmo grupo profissional, isto, porque esta identidade perpassa pela construção biográfica e relacional de cada indivíduo e é cada vez mais difícil:

[...] conceber a vida profissional como um padrão em que a ocupação de um mesmo emprego e a realização de uma mesma função, nos mesmos contextos, em toda a vida ativa, seja igual para todos os membros.

Noutras palavras, a trajetória profissional envolve elementos da história de vida de cada sujeito e a sua participação nas relações sociais de trabalho, é um processo dinâmico e dialético, pois envolve além de expectativas pessoais e subjetivas também determinações exteriores (TEIXEIRA, 2009).

Partindo desse entendimento, se procurou saber dos entrevistados como iniciaram na função de coordenadores pedagógicos, três dos pesquisados admitiram que ingressaram na escola como professores e com um tempo, por indicação dos gestores foram readaptados de função. Com exceção da coordenadora C3, que foi indicada pela Unidade Regional de Educação (URE) do seu município.

Segundo o relato do coordenador $\mathrm{Cl}$, ele atuava como professor de Química, mas assumiu a coordenação pedagógica por indicação em um momento de crise da escola que passava por sérios problemas de rebeldia dos alunos, difícil relacionamento entre gestão e professores e falta de pessoal administrativo:

[...] Nesse contexto eu ainda professor de química fui convidado no finalzinho do ano para fazer parte da equipe de gestão da escola, aí nesse momento eu comecei a estudar por conta própria né, pra dar conta do recado, [...] naquele momento eu achava que eu precisava então compreender alguma coisa daquele componente e comecei a ir atrás (C1). 
A coordenadora C2 ingressou na escola como pedagoga e com o afastamento da antiga coordenadora por problemas de saúde, foi indicada a exercer essa função, especialmente por ter direcionado como professora vários processos formativos na escola. Segundo ela, esse momento de readaptação de função representou uma ruptura muito grande,

[...] porque não iria estar mais naquele espaço de sala de aula e ia ter que desenvolver algo que eu admirava, mas que não me via muitas vezes fazendo, que era esse trabalho de coordenador, de acompanhar o desenvolvimento do ensino- aprendizagem dos alunos de toda a escola (C2).

Já a coordenadora C3, exercia em sua escola a função de professora e foi indicada a trabalhar na coordenação pedagógica pela Unidade Regional de Educação (URE) de Rosário, contudo, ela já havia atuado antes como supervisora pedagógica em outra escola da rede estadual de ensino que foi municipalizada.

Por estes depoimentos, é possivel dizer que, na prática, não há prérequisitos de formação profissional para atuar na coordenação pedagógica, bastando a experiência docente e a ratificação da Secretaria de Educação, URE ou direção para a indicação na função. Deste modo, muitos destes profissionais buscam uma formação mais específica na área somente quando já estão exercendo a função, geralmente não havendo um interesse ou preparação anterior (FONSECA, 2013).

No caso dos demais entrevistados, elas já ingressaram em suas escolas devidamente como coordenadoras. A coordenadora C4 assumiu esta função por recomendação de outros gestores das escolas com quem trabalhou na rede estadual de ensino, que foram fechadas e municipalizadas na região. No entanto, mesmo sendo indicada afirma: "Na verdade eu nem escolhi, né, mas se eu pudesse escolher era só o que eu faria hoje" (C4).

A coordenadora C5, também ingressou na escola como coordenadora pedagógica, mas foi indicada a trabalhar nesta função pela Semed de Santa Inês, tendo em vista que a escola passava por sérios problemas de evasão escolar com a modalidade EJA. Essa escolha se 
justificou, portanto, pelo seu ótimo desempenho em outras instituições da rede municipal de ensino com esse público. Contudo, o que mais a motivou a permanecer na função foi o seu interesse pela educação.

Vimos que apesar de terem sido indicados os coordenadores pesquisados decidiram permanecer nesta função, o que para autores como Teixeira (2009) também implica em decisão pessoal, uma vez que os fatores subjetivos igualmente tiveram peso nesta decisão.

Diferente dos demais, a coordenadora C6 atuou nesta função em uma escola da rede estadual de ensino e diz:

[...] primeiro eu apenas aceitei o convite e depois eu fui achando que eu poderia contribuir, [...] essa dinâmica de propor uma coisa nova, uma metodologia nova, um acompanhamento novo isso me fascina. Aí eu fui, fui estudando e [...] amo ser professora que é a minha primeira paixão e aí depois eu fui para a coordenação pedagógica e me apaixonei (C6).

No entanto, no período em que se desenvolveu esta pesquisa, ela tornou-se Supervisora e Técnica Pedagógica da URE de Santa Inês. E hoje, a mesma, realiza o acompanhamento pedagógico em 3 escolas da rede de ensino estadual (duas escolas de Ensino Médio Regular e um Centro de Educação Integral de Ensino Médio) desenvolvendo, particularmente com os professores e gestores, formações em serviço.

Por estes relatos, percebe-se que "[...] o coordenador pedagógico é, antes de tudo, um professor que aceita assumir a função de fazer parte da equipe gestora da escola junto com o diretor e o diretor-adjunto" (OLIVEIRA, 2011 , p.2). Mas quando indicados, "[...] o nó da questão é que o grupo possa ver o coordenador com desconfiança por não ter apostado em seu perfil, nem se quer ter discutido a sua atuação e expectativas quanto à função" (ROCHA, 2015, p.7). É nesse sentido, que traçar o perfil profissional destes coordenadores pedagógicos constitui um referencial importante para esses profissionais de como realizar sua função e de como se pretende significá-la. 


\section{Alguns aspectos sobre formação e trabalho dos coordenadores pesquisados}

Tendo já discutido como estes profissionais tornaram-se coordenadores pedagógicos, neste instante, vale a pena evidenciarmos o seu perfil profissional por formação acadêmica, conforme expressa o quadro 2.

\section{QUADRO 2- Perfil profissional dos coordenadores pedagógicos pesquisados por formação acadêmica}

\begin{tabular}{|c|c|c|c|c|}
\hline $\begin{array}{l}\text { Coordenador } \\
\text { pedagógico }\end{array}$ & $\begin{array}{l}\text { Formação } \\
\text { Inicial }\end{array}$ & $\begin{array}{l}\text { Graduação/ } \\
\text { Ano } \\
\text { de formação }\end{array}$ & $\begin{array}{l}\text { Disciplinas relacionadas } \\
\text { a gestão escolarb/ } \\
\text { carga horária }\end{array}$ & $\begin{array}{l}\text { Outras } \\
\text { especiali- } \\
\text { zações }\end{array}$ \\
\hline$C 1$ & $\begin{array}{l}\text { Licencia- } \\
\text { tura em } \\
\text { Química }\end{array}$ & $\begin{array}{l}\text { Universidade } \\
\text { Estadual do } \\
\text { Maranhão- } \\
\text { UEMA (2005) }\end{array}$ & $\begin{array}{l}\text { Estrutura e funcionamento } \\
\text { do ensino fundamental e } \\
\text { médio (60h) }\end{array}$ & Não possui \\
\hline C2 & $\begin{array}{l}\text { Licencia- } \\
\text { tura em } \\
\text { Pedagogia }\end{array}$ & UFMA (2012) & $\begin{array}{l}\text {-Princípio e Metodologia } \\
\text { de Orientação Educacional } \\
\text { l e II (75 h/ 90h) } \\
\text { - Estágio em Orientação } \\
\text { Educacional I e II (90 h/ 135h) }\end{array}$ & Não possui \\
\hline C3 & $\begin{array}{l}\text { Licencia- } \\
\text { tura em } \\
\text { Pedagogia }\end{array}$ & UEMA (2008) & $\begin{array}{l}\text {-Gestão Escolar (60h) } \\
\text {-Princípio e Metodologia } \\
\text { de Orient. Sup. Escolar (60h) }\end{array}$ & $\begin{array}{l}\text { Psicopeda- } \\
\text { gogia }\end{array}$ \\
\hline C4 & $\begin{array}{l}\text { Licencia- } \\
\text { tura em } \\
\text { Pedagogia } \\
\text { e } \\
\text { Magistério }\end{array}$ & UEMA (2014) & $\begin{array}{l}\text {-Gestão Escolar (60h) } \\
\text { - Supervisão escolar (60h) } \\
\text { - Orientação educacional } \\
\text { (60h) } \\
\text { - Estágio em áreas } \\
\text { específicas- coordenação } \\
\text { pedagógica (135h) }\end{array}$ & Não possui \\
\hline C5 & $\begin{array}{l}\text { Licencia- } \\
\text { tura em } \\
\text { Geografia } \\
\text { e } \\
\text { Pedagogia }\end{array}$ & $\begin{array}{l}\text { Instituição } \\
\text { Superior } \\
\text { de Educação } \\
\text { São Judas } \\
\text { Tadeu (2012) }\end{array}$ & $\begin{array}{l}\text {-Organização e Gestão } \\
\text { do Trabalho escolar (80h) } \\
\text { - Princípio e Métodos de } \\
\text { Supervisão Educacional I } \\
\text { (80h) e II } \\
\text { - Estágio Super. em } \\
\text { Supervisão Educacional } \\
\text { (120h) }\end{array}$ & $\begin{array}{l}\text {-Psicopeda- } \\
\text { gogia } \\
\text { - Gestão } \\
\text { Ambiental } \\
\text { - Gestão, } \\
\text { Orientação e } \\
\text { Supervisão } \\
\text { pedagógica }\end{array}$ \\
\hline C6 & $\begin{array}{l}\text { Licencia- } \\
\text { tura em } \\
\text { Letras }\end{array}$ & UEMA (1998) & $\begin{array}{l}\text {-Estrutura e Funcionamento } \\
\text { do Ensino I e II graus (60h) }\end{array}$ & $\begin{array}{l}\text {-Gestão } \\
\text { Educacional } \\
\text {-Consultora } \\
\text { em Gestão de } \\
\text { Pessoas e } \\
\text { Coach } \\
\text { Executiva }\end{array}$ \\
\hline
\end{tabular}

Fonte: Diniz (2018).

\footnotetext{
${ }^{6}$ Essas disciplinas, que foram extraídas dos históricos das Licenciaturas dos coordenadores pesquisados são aquelas em que foi possível detectar relação com os conteúdos da gestão escolar (DINIZ, 2018, p.91).

7 Liderança ligada ao meio corporativo que busca resultados de pessoas e um ambiente de trabalho favorável ao desenvolvimento dos profissionais (O QUE ..., 2018).
} 
Percebe-se que há no grupo de entrevistados a predominância de profissionais formados no Curso de Pedagogia, temos apenas dois coordenadores que possuem outras especializações. Contudo, no que diz respeito à formação continuada, atualmente, todos possuem qualificação necessária para atuarem como coordenadores pedagógicos. E a metade destes sujeitos, além do Curso de Especialização em Coordenação Pedagógica ainda possuem outras especializações na área educacional, inclusive, muitos deles em entrevista esboçaram interesse em realizar também especializações stricto sensu, como o Mestrado em Educação.

Cristov (2010, p. 9), nessa direção, evidencia que "[...] a realidade muda e o saber que construímos sobre ela precisa ser revisto e ampliado sempre." Portanto, acreditamos que estes entrevistados estão à procura de uma qualificação adequada e desejam com isso alcançar um melhor desenvolvimento profissional.

Em se tratando do trabalho, sabe-se que esta é uma atividade na qual as pessoas transformam a sua realidade e se transformam, construindo a sua cultura e humanizando-se (ALVES; BARBOSA, 2011). Assim, no quadro 3, a seguir, buscamos destacar dos coordenadores pesquisados alguns aspectos do seu trabalho, identificando o tempo de exercício na função de professores, coordenadores pedagógicos e sua carga horária semanal de trabalho.

QUADRO 3- Perfil profissional dos coordenadores pedagógicos pesquisados por tempo de exercício na função de professor, coordenador pedagógico e carga horária semanal de trabalho

\begin{tabular}{|c|l|l|l|}
\hline $\begin{array}{c}\text { Coordenador } \\
\text { pedagógico }\end{array}$ & $\begin{array}{c}\text { Tempo de } \\
\text { exercício como } \\
\text { professor }\end{array}$ & $\begin{array}{c}\text { Tempo de exercício } \\
\text { como coordenador } \\
\text { Pedagógico }\end{array}$ & $\begin{array}{c}\text { Carga horária } \\
\text { semanal de trabalho }\end{array}$ \\
\hline C1 & 3 anos & 9 anos & $40 \mathrm{~h}$ semanais \\
\hline C2 & 24 anos & 8 anos & $32 \mathrm{~h}$ semanais \\
\hline C3 & 27 anos & 1 ano e meio & $40 \mathrm{~h} \mathrm{semanais}$ \\
\hline C4 & 8 anos & 4 anos & $60 \mathrm{~h}$ semanais \\
\hline C5 & 23 anos & 5 anos & $20 \mathrm{~h}$ semanais \\
\hline
\end{tabular}



C6
30 anos
4 anos
$40 \mathrm{~h}$ semanais

Fonte: Diniz (2018).

Notamos que o quadro dos entrevistados é composto por pessoas experientes e que estão em pleno desenvolvimento profissional, pois com exceção de dois deles ( $\mathrm{Cl}$ e $\mathrm{C} 4$ ), a maioria possui mais de 10 anos de trabalho na carreira docente. Tal característica, de possuírem uma boa experiência como professores antes de atuarem como coordenadores pedagógicos se refere à própria historicidade da função que nasce estruturada como uma função do Magistério, conforme assinala Alves (2007).

Sobre o tempo de exercício na função de coordenador pedagógico, segundo Ferri (2013), é comum que os professores apresentem períodos de amadurecimento profissional se envolvendo em novas atividades e diversificando o seu campo de atuação nas escolas. É o que também notamos com este grupo de pesquisados, já que a metade se encontra na faixa dos 5 anos ou mais na coordenação pedagógica, com exceção de três deles (C3, C4 e C6).

No que diz respeito à carga horária semanal de trabalho, 2 dos coordenadores entrevistados ( $\mathrm{Cl}$ e $\mathrm{C} 5$ ) trabalham em outras instituições desenvolvendo a atividade docente, além da coordenação pedagógica. Por outro lado, duas das coordenadoras pesquisadas (C2 e C4) desenvolvem esta mesma função em outras instituições e os demais entrevistados, possuem carga horária total de 40 horas na mesma instituição.

Esses sujeitos, portanto, cumprem dupla ou até mesmo tripla jornada de trabalho em mais de uma escola e rede de ensino para terem melhores rendimentos salariais (ALVES, 2007). A essa discussão, cabe acrescentar que os coordenadores Cl e C3 também ocupam em suas escolas o cargo efetivo de gestores auxiliares.

Assim, como aponta Lima (2016), é comum que nas escolas públicas o quadro de profissionais seja insuficiente para suprir as demandas diárias, o que leva muitos profissionais como o coordenador pedagógico a desdobrarse em novas e outras funções na escola. 


\section{O que deve compor o perfil profissional do coordenador pedagógico na visão dos pesquisados}

De acordo com Rivas (2009), levando em conta as análises de Vasconcelos, o coordenador pedagógico para exercer a sua profissionalidade precisa desenvolver três dimensões: conceitual, procedimental e atitudinal. A respeito de cada uma delas, a dimensão conceitual relaciona-se aos conhecimentos e formação específica que os coordenadores pedagógicos precisam buscar para a realização do seu trabalho. A dimensão procedimental se refere ao saber-fazer em que 0 coordenador pedagógico preocupado com a intencionalidade do seu trabalho escolhe um caminho coerente para desenvolver da melhor forma a sua função. Já a terceira e última dimensão, a atitudinal, corresponde à postura destes profissionais frente à possibilidade de mudança do outro e isso, inclui a confiança de que os docentes podem modificar sua visão e prática pedagógica.

Sob esta ótica, tomando por base as dimensões a pouco discutidas, se procurou saber dos próprios entrevistados o que deve compor o perfil profissional de um coordenador pedagógico. Em relação à dimensão conceitual, colocamos em destaque a fala de 3 dos entrevistados. O coordenador $\mathrm{Cl}$ evidenciou que como um componente fundamental da gestão escolar, o coordenador pedagógico precisa ter clareza de suas ideias por meio de uma boa formação. Para tal, a coordenadora C6 ressaltou que ele precisa ser competente pedagogicamente. Já a coordenadora C3 relatou que o coordenador pedagógico "[...] é o ponto de encontro [...] é o mediador entre o núcleo gestor e o corpo docente, entre os docentes e os discentes" (C3). Porém, segundo ela, este profissional "[...] se envolve em tudo, ele participa de tudo, ele articula, ele faz de tudo um pouquinho [...] não só as questões pedagógicas (C3).

Sobre o assunto, Rabelo (2011) nos diz que é necessário que o coordenador pedagógico estabeleça limites para as urgências e 
multiplicidades do seu cotidiano, acolhendo com prioridade as questões pedagógicas, em especial a formação em serviço dos docentes.

No que tange a dimensão procedimental, como relevante pontuamos - que diz a coordenadora C2, de acordo com ela, o coordenador pedagógico deve ter como perfil:

[...] analisar as situações e ter muito cuidado na hora que vai tomar qualquer decisão quer seja com professor, quer seja com aluno, quer seja com o pai do aluno, porque a gente tá trabalhando com o lado humano então eu sou muito preocupada com isso, certo, como é que eu vou dizer tal coisa para uma criança, como é que eu vou lidar com o lado emocional do sujeito então eu sou muito preocupada com o lado emocional.

Esta questão de cunho emocional que evidencia a coordenadora C2 revela a importância de o coordenador pedagógico lidar com as relações interpessoais, uma vez que a busca pela qualidade, como assinala Libâneo (2004), também envolve trabalhar com seres humanos para ajudá-los e orientá-los a se constituírem como sujeitos.

Já a coordenadora $\mathrm{C} 4$, em seu depoimento destacou que este profissional deve sempre ter o interesse em fazer um bom trabalho. Para isso, segundo a própria, ele deve preocupar-se em otimizar a sua função e ter o interesse e motivação para melhorar o processo de ensino-aprendizagem. A coordenadora C6, corroborando com esta colocação, nos diz que o coordenador também precisa ter disposição para a mudança, aceitando novos desafios sempre que necessário. Para a coordenadora C5, é fundamental que ele, além de organizado e disciplinado, siga uma proposta de trabalho coerente com o projeto pedagógico da escola:

O perfil do coordenador pedagógico para mim (pensativa) a essência está na proposta pedagógica dele, na proposta de trabalho, naquilo que ele tem a oferecer né. Então, ele tem que tá disposto a isso né, ele precisa, que é o que me cobro muito né (C5).

Congruente ao exposto, acreditamos bem como Domingues (2014, p. 114) que, na escola, cabe ao coordenador pedagógico "[...] coordenar as atividades de modo a promover uma consciência de si e do outro, ligadas por um projeto coletivo que estabeleça objetivos e metas comuns". 
Por fim, com relação à dimensão atitudinal, 3 dos coordenadores entrevistados evidenciaram em seus relatos a questão da comunicação. Para as coordenadoras $\mathrm{C} 1$ e C2, o coordenador deve ter uma boa relação interpessoal, bem como saber ouvir e comunicar-se. Já conforme a coordenadora C6,

[...] o coordenador pedagógico trabalha muito com as informações, com as orientações então se ele não tem uma comunicação assertiva ele corre o risco de não ser bem entendido e as coisas não fluem, então a comunicação para mim é algo importantíssimo no processo de sucesso mesmo do coordenador pedagógico.

Neste ponto, defendemos que para um processo democrático, coordenadores e professores, investidos de papéis e saberes diferentes podem por meio da comunicação, "[...] buscar um encontro fecundo, cujo fruto seja a construção de uma prática pedagógica mais consistente, enriquecida e criativa (LIMA; SANTOS, 2007, p. 87)".

Ainda sobre isso, a coordenadora C6, acrescenta outro fator relevante em seu depoimento:

[...] ele tem que ser empático também porque quando a gente diz: Lá vem o coordenador pedagógico todo mundo já sai se benzendo, então isso é a falta de empatia em minha opinião. Diferente de quando a gente diz: graças a Deus lá vem o coordenador ele vai me ajudar nessa fragilidade aqui, muitas das vezes essa não é a visão que a gente tem da maioria dos coordenadores pedagógicos.

Com esta fala, ressalta-se a importância, assim como também revelou a coordenadora $\mathrm{C} 4$, do coordenador pedagógico ter um perfil responsável e compromissado e ser visto como um parceiro da comunidade escolar, tendo em vista que ele atua com ou sobre um grupo para manter a escola coesa e integrada (RABELO, 2011).

Diferente dos demais, a coordenadora C5 evidencia que 0 coordenador pedagógico precisa ser um inovador.

[...] as pessoas querem coisas novas, nós estamos no auge do século 21 e ninguém quer nada ultrapassado, todo mundo quer coisas novas e a inovação ela entra no currículo, ela entra nas técnicas, ela entra, por exemplo, aqui que nós trabalhamos muito, nos projetos, mas com oficinas, então, é inovador por que termina sendo um projeto, mas um projeto que vai gerar renda, que vai fazer com que esse sujeito tenha uma profissão (C5). 
A nosso ver, a questão da inovação perpassa pela atitude deste sujeito gerar transformações e renovações no espaço escolar. Maldonado (2015), em se tratando deste tema indica que no processo de ensinoaprendizagem as inovações são necessárias e devem ser revistas com maior atenção e olhares menos céticos pelos educadores e seus pares.

Com as respostas obtidas, observamos que mesmo vivendo em contextos tão específicos e singulares, os coordenadores pedagógicos trazem alguns pontos em comum em suas falas, destacando além de atitudes como comunicação, participação e comprometimento, a relevância deste profissional ter uma formação específica de qualidade. Deste modo, não restam dúvidas de que todos os aspectos citados são fundamentais para a composição de um perfil profissional do coordenador, que melhor caracterize a real dimensão de seu fazer pedagógico.

\section{Considerações finais}

Diante deste estudo, concluiu-se que a função do coordenador pedagógico está em construção, caracterizada por profissionais de diversos perfis e atribuições na escola. Por essa razão, o seu perfil profissional é hoje um desafio marcado por ambiguidades e dificuldades que precisam ser superadas.

Nessa perspectiva, é preciso garantir que nas escolas a função primeira de formação em serviço a ser realizada por esse profissional seja exercida como forma de enriquecer o trabalho docente e garantir junto a comunidade escolar a melhoria da qualidade de ensino. Assim, defende-se um perfil com características pessoais e profissionais que sejam fundamentais para o exercício desta atividade. Dentre as suas habilidades pessoais, é essencial que o coordenador pedagógico exerça a capacidade na escola de liderar, de motivar, de trabalhar em equipe, de observar e gerenciar conflitos. Ainda no que refere ao seu perfil, ele necessita de conhecimentos gerais e específicos para a realização do seu trabalho, buscando sempre se atualizar para obter uma maior qualificação. 
Com esse entendimento, no rol de políticas públicas formativas dedicadas a gestão escolar, o Curso de Especialização em Coordenação Pedagógica revelou-se, então, no Maranhão, uma experiência positiva que contribuiu para o fortalecimento do perfil profissional dos coordenadores pedagógicos egressos. Já que ofereceu, no estado, a oportunidade destes profissionais terem acesso a referenciais teóricos que pudessem ajudá-los a sustentar a sua prática, fazendo-os repensar sobre a especificidade do seu trabalho e reconhecendo o seu papel de importância para a articulação, formação e transformação do espaço escolar.

Contudo, as análises construídas nesta investigação ainda nos levam a afirmar que há muito a ser feito para que, na prática, o perfil profissional do coordenador pedagógico ganhe certa unidade. Com efeito, modificar a visão e a postura com relação ao coordenador pedagógico envolve muitos debates a respeito das representações históricas, subjetividades e expectativas da própria comunidade escolar quanto a esta função.

Tal discussão se constitui, portanto com um alerta para que os sistemas públicos e a comunidade escolar não deixem de repensar a função do coordenador, assim, corroborando com mais pistas para se refletir a respeito da identidade e formação destes sujeitos e, consequentemente sobre o seu perfil profissional.

\section{Referências}

ALVES, N. N. L. Coordenação pedagógica na educação infantil: trabalho e identidade de profissional na rede municipal de ensino de Goiânia. 2007. 286f. Tese (Doutorado em Educação) - Universidade Federal de Goiás, Goiânia, 2007.

\section{ALVES, N. N. L.; BARBOSA, I. G. Identidade profissional da coordenação} pedagógica na educação infantil, 2011. Disponível em: www.anpae.org.br/simposio2011/cdrom2011/PDFs/trabalhosCompletos/com unicacoesRelatos/0415.pdf. Acesso em: 24 abr. 2019.

ALVES-MAZZOTTI, A. J. Usos e abusos dos estudos de caso. Cadernos de Pesquisa, São Paulo, v. 36, n. 129, p. 637-651, set./dez. 2006. Disponível em: http://www.scielo.br/scielo. 
php?pid=\$010015742006000300007\&script=sci_abstract\&tlng=pt. Acesso em: 24 abr. 2019.

BRASIL. Ministério da Educação. Curso para diretores aprimora a prática da gestão escolar. [201-]. Disponível em:

http://portal.mec.gov.br/component/tags/tag/33600. Acesso em: 24 abr. 2019.

BRASIL. Ministério da Educação. Projeto Pedagógico do Curso de PósGraduação lato sensu em Coordenação Pedagógica. Brasília / DF, abril de 2009.

CHRISTOV, L. H. S. Educação Continuada: função essencial do coordenador pedagógico. In: BRUNO, E. B. G.; CHRISTOV, L. H. S. (Orgs.). O coordenador pedagógico e a educação continuada. São Paulo: Edições Loyola, 2010.

CHÚ, E. N. C. Perfil do coordenador pedagógico, 2012. Disponível em: coordenadoraerika. blogspot.com/2012/08/perfil-do-coordenadorpedagogico_28.html. Acesso em: 27 abr. 2019.

DOMINGUES, I. O coordenador pedagógico e o desafio da formação contínua do docente na escola. 2009. 235 f. Tese (Doutorado em Educação) - Faculdade de Educação da Universidade de São Paulo, São Paulo, 2009.

DOMINGUES, I. O coordenador Pedagógico: e a formação contínua do docente na escola. 1. ed. São Paulo: Cortez, 2014

DINIZ, C. C. Formação continuada e prática de coordenadores pedagógicos no Maranhão: em cena o programa nacional escola de gestores. 2018, 170 . Dissertação (Mestrado em Educação) - Universidade Federal do Maranhão, Programa de Pós-Graduação em Educação, São Luís, 2018.

DOTTA, L. T.; LOPES, A.; GIOVANNI, L. M. Educação Superior e formação de professores: o papel da investigação na constituição identitária profissional docente. Perspectiva, Florianópolis, v. 29, n. 2, p. 561-594, jul./dez. 2011.

DUARTE, N. Conhecimento tácito e conhecimento escolar na formação do professor (porque Donald Shön não entendeu Luria). Educ. Soc., Campinas, vl. 24, n. 83, p. 601-625, 2003.

FONSECA, E. O. Os percursos formativos dos docentes que atuam na gestão escolar. 2013. 151 f. Dissertação (Mestrado em Educação) - Universidade Estadual do Ceará, Fortaleza, 2013. 
FREITAS, L. C. Os reformadores empresariais da educação e a disputa pelo controle do processo pedagógico na escola. Educação e Sociedade.

Campinas/ SP: Cedes, v. 35, n. 129, p. 1085-1113, out/dez. 2014.

FERRI, T. H. J. B. O trabalho e os desafios do professor coordenador na rede municipal de Rio Claro. 2013. 133 f. Dissertação (Mestrado em Educação) Universidade Estadual Paulista Júlio de Mesquita Filho, São Paulo, 2013.

FORTUNA, M. L. A. Do Professor a Gestor: as múltiplas funções do coordenador pedagógico, 2011. Disponível em:

http://www.anpae.org.br/simposio201 1/cdrom201 1/PDFs/trabalhosCompleto s/comunicacoesRelatos/0377.pdf. Acesso em: 24/04/2019.

GHEDIN, E. Professor Reflexivo: da alienação da técnica à autonomia da crítica. In: PIMENTA, S. G.; GHEDIN, E. (orgs.) Professor Reflexivo no Brasil: gestão e crítica de um conceito. São Paulo: Cortez, 2002.

O QUE é coaching executivo? Instituto Brasileiro de Coaching, 2018.

Disponível em: https://www.ibccoaching.com.br/portal/coaching/o-que-ecoaching-executivo/. Acesso em 13 jun. 2019.

LIBÂNEO, J. C. Organização e gestão da escola: teoria e prática. 5. ed. revista e ampliada. Goiânia: Editora Alternativa, 2004.

LIBÂNEO, J. C. Ainda as perguntas: o que é pedagogia, quem é o pedagogo, o que deve ser o curso de Pedagogia. In: PIMENTA, S. G. (org.).

Pedagogia e pedagogos: caminhos e perspectivas. São Paulo: Cortez, 2002.

LIMA, P. G.; SANTOS, S. M. O coordenador pedagógico na educação básica: desafios e perspectivas. Educare et Educare, v. 2, n.4, p.77-90, jul./dez. 2007. Disponível em: http://e-

revista.unioeste.br/index.php/educereeteducare/article/view/1656/1343 Acesso em 29 out. 2018.

LIMA, S. M. G. Coordenador pedagógico e seu processo formativo:

perspectivas e limites de trabalho. 2016.149 f. Dissertação (Mestrado em Educação) - Universidade de Brasília, Brasília-DF, 2016.

MALDONADO, L. Gestão escolar: para uma práxis transformadora: uma escola pública inovadora EMEF Desembargador Amorim Lima, 2015. $113 f$. Dissertação (Mestrado em Educação) - Pontifícia Universidade Católica do Rio Grande do Sul, Programa de Pós-Graduação em Educação (PUCRS). Porto Alegre, 2015.

MINAYO, M. C. S.(org). Pesquisa social: Teoria, método e criatividade. 29. ed. Petrópolis, RJ: Vozes, 2010. p. 61-77. 
OLIVEIRA, J. C. A identidade do coordenador pedagógico: um estudo nas escolas públicas municipais da cidade do Rio de janeiro. 2011. Disponível em: https://paginas.vepa.br/seer/index.php/cocar/article/download/67/66. Acesso em 24 abr. 2019.

PARO, V. H. Administração escolar: introdução crítica. 16. ed. São Paulo: Cortez, 2010 [1986].

PLACCO, V. M.N. S.; SOUZA, V. L. T.; ALMEIDA, L. R. O coordenador pedagógico: aportes à proposição de políticas públicas. Cad. Pesquisa. São Paulo, v. 42, n. 147, dez. 2012a.

PLACCO, V. M.N. S.; SOUZA, V. L. T.; ALMEIDA, L. R. Coordenador pedagógico (CP) e o cotidiano das escolas: práticas educativas e formação de professores. In: ENDIPE - Didática e Práticas de Ensino: compromisso com a escola pública, laica, gratuita e de qualidade. 16., Campinas: Junqueira e Marin Editores, v. 2, 2012b, p. 3092-3104.

POUPART, J. A entrevista de tipo qualitativo: considerações epistemológicas, teóricas e metodológicas. In: POUPART, J. et al. A pesquisa qualitativa: enfoques epistemológicos e metodológicos. 2.ed. Petrópolis: Vozes, 2010. p. 215- 253.

RABELO, C.D. Coordenador Pedagógico Escolar Municipal: identidade, trabalho e atitudes de um profissional em ressignificação. In: SIMPÓsIO BRASILEIRO DE POLÍTICA E ADMINISTRAÇÃO DA EDUCAÇÃO. 25.,; CONGRESSO IBERO-AMERICANO DE POLÍTICA E ADMINISTRAÇÃO DA EDUCAÇÃO. 2., 2011. São Paulo. Anais [...] São Paulo: ANPAE, 2001. Disponível em:

http://www.anpae.org.br/simposio2011/cdrom201 1/PDFs/trabalhosCompleto s/comunicacoesRelatos/0111.pdf. Acesso em 20 set. 2018.

RICHARDSON, R.J. Pesquisa Social: métodos e técnicas. 3. ed. São Paulo: Atlas, 1999.

RIBEIRO, R.N.C. O coordenador pedagógico na escola pública: Dilemas, contradições e desafios de um profissional inicial. Revista Reflexão e Ação, Santa Cruz do Sul, v. 24, n.2, p. 59-78, maio/ago, 2016. Disponível em: http://online.unisc.br/seer/index.php/reflex/index, Acesso em: 24 abr. 2019.

RIVAS, S.C. A mediação na prática cotidiana da coordenação pedagógica. Revista FACED, Salvador, n.15, jan./jul. 2009.

ROCHA, C.C. Perfil do coordenador pedagógico: obstáculos e pistas de ação, 2015. Disponível em: https://www.sinprodf.org.br/wpcontent/uploads/2015/03/perfil-do-coordenador-pedagu00d3gico-e-pistas- 
de-av00c7v00c3o-para-organizav00c7v00c3o-e-planejamento.pdf. Acesso em 24 abr. 2019.

SALGUEIRO, S.I.D. Perfil do Supervisor pedagógico do $1^{\circ}$ CEB: um estudo de caso. 179 f. Dissertação (Mestrado em Educação) - Escola Superior de Educação de Santarém, 2014. Disponível em:

https://repositorio.ipsantarem.pt/bitstream/10400.15/1 124/1/Disserta\%C3\%A7 \%C3\%A30\%20-\%20S\%C3\%ADlvia\%20lsabel\%20Delgado\%20Salgueiro.pdf. Acesso em: 17 maio 2019.

SANTOS, T.S. O perfil do pedagogo como coordenador pedagógico: uma realidade vivenciada no município de Valença-BA, 2014. Disponível em: editorarealize.com.br/revistas/fiped/trabalhos/Modalidade_2datahora_16_06 _2014_08_37_18_idinscrito_884_7e9770b996d1 4cd483540d676c6b0304.pdf. Acesso em: 25 de maio de 2019.

SILVA, D. M. O coordenador pedagógico e os ambientes virtuais de aprendizagem - um espaço para a formação de professores. 2015.86 f. Dissertação (Mestrado Profissional em Educação) - Pontifícia Universidade Católica de São Paulo, São Paulo, 2015.

SOUZA, R. A. Formação de professores/ coordenadores pedagógicos a partir do programa Nacional escola de Gestores: a experiência no Tocantins. 2016. 276 f. Tese (Doutorado em Educação) - Universidade de Brasília, Brasília, 2016.

TEIXEIRA, C. S. M. De supervisor escolar à coordenador pedagógico: o movimento de constituição da identidade profissional. 2009. 148 f Dissertação (Mestrado em Educação) - Universidade Federal do Piauí, Teresina, 2009.

UNIVERSIDADE FEDERAL DO MARANHÃO. Relatório Final do Curso de Especialização em Coordenação Pedagógica, 2017. Disponível em: <http://simec.mec.gov.br>. Acesso em: 12 mar. 2018.

UNIVERSIDADE FEDERAL DO MARANHÃO. Resolução No 1265 CONSEP, de 14 abril de 2015. Altera o Regimento Geral dos Cursos de Pós-Graduação Lato Sensu da UFMA. 2015. Disponível em:

http://www.ufma.br/portalUFMA/edital/x7YOchFOTktXtwk.pdf. Acesso em 28 fev. 2019.

VÁZQUEZ, A. D. Filosofia da práxis. Tradução de Luiz Fernando Cardoso. 2. ed. Rio de Janeiro: Paz e Terra, 1977, 454 p.

VIEIRA, H. P. O perfil profissional do pedagogo e práxis: relatos de experiências na educação básica. In: SEMANA DE EDUCAÇÃO DA UNIVERSIDADE ESTADUAL DO CEARÁ, 22., 2015. Anais [...]. Universidade Estadual do Cearé, 2015. Disponivel em: 
http://www.uece.br/eventos/semanadeeducacaovece/anais/trabalhos_co mpletos/210-12319-26092015-204548.pdf. Acesso em 26 jun. 2019.

Recebido em: 02 de janeiro de 2020

Aprovado em: 24 de maio de 2020

Publicado em: 04 de setembro de 2020 